\title{
PERANCANGAN INSTALASI LISTRIK PADA GEDUNG MARKAS KOMANDO DIREKTORAT KEPOLISIAN PERAIRAN DAN UDARA KEPOLISIAN DAERAH SULAWESI TENGAH DI DESA WANI
}

\author{
Mohammad Agrimansyah ${ }^{1)}$, Nurhani Amin ${ }^{2)}$, Muh. Sarjan ${ }^{3)}$ \\ ${ }^{2,3)}$ Dosen Teknik Elektro Universitas Tadulako \\ Program Studi S1 Teknik Elektro, Fakultas Teknik, Universitas Tadulako \\ E-mail : agree2121@gmail.com
}

\begin{abstract}
In office buildings, electrical energy is needed to meet the needs of lighting to electronic equipment used in the building. To support all of that, a reliable electrical installation system is needed so that all office activities can run well without causing significant problems. Therefore the planning of the electrical installation system in a building must refer to the applicable rules and regulations in accordance with PUIL and SNI.

The design carried out refers to PUIL 2011, SNI 03-6575-2001 (Lighting System Design Procedures). The entire electrical installation system gets a 3 Phase supply from PLN. The total power in this building is 80000 watts, so the power needed from PLN to connect is $160 \mathrm{KVA}$. Conductors used in this installation, use cables with NYM and NYY types with varying sizes in accordance with the calculation of the conveying CRC that has been done.
\end{abstract}

Keyword : Design, Electrical Installation, PUIL 2011, SNI

\section{PENDAHULUAN}

Sulawesi Tengah merupakan provinsi yang pembangunan infrastrukturnya masih dalam tahap perkembangan. Apalagi setelah tertimpa bencana alam besar pada tanggal 28 September 2018 yang lalu, tentunya ada perbaikan/renovasi maupun pembangunan kembali ditempat-tempat atau gedung yang diperlukan guna menunjang dan membangkitkan kembali perkembangan provinsi Sulawesi Tengah dari sisi Politik, Sosial maupun Ekonomi. Hal ini tentunya memacu kembali kebutuhan akan energi listrik karena setiap bangunan membutuhkan energi listrik seperti rumah tinggal, industri, perkantoran, bangunan komersil serta sekolah atau kampus. Oleh kerena itu, diperlukan perencanaan instalasi listrik yang memenuhi standar berdasarkan peraturan yang berlaku, sesuai dengan Standar Nasional Indonesia (SNI) dan Persyaratan Umum Instalasi Listrik (PUIL).

Gedung Markas Komando Direktorat Kepolisian Perairan dan Udara Kepolisian Daerah Sulawesi Tengah merupakan gedung yang masih dalam tahap pembangunan yang berlokasi di Desa Wani Kecamatan Tawaeli Kabupaten Donggala. Kondisi inilah yang membuat penulis ingin menyusun perencanaan instalasi listrik sesuai dengan Standar Nasional Indonesia (SNI) dan Persyaratan Umum Instalasi Listrik (PUIL). Pada perencanaan instalasi gedung ini, penulis akan menggunakan metode perhitungan dan analisa sebagai pendekatan untuk menentukan spesifikasi komponenkomponen yang akan digunakan yang mengacu pada peraturan dan ketentuan berdasarkan PUIL 2011 dan sesuai dengan Standar Nasional Indonesia. [1] Sehingga nantinya proses perkantoran yang dilaksanakan dapat berjalan dengan efektif dan efisien. 


\section{METODE PENELITIAN}

\subsection{Tinjauan Pustaka}

Penelitian mengenai perancangan instalasi listrik telah banyak dilakukan tapi tempat dan metode yang digunakan berbeda. Berikut jurnal- jurnal melalui internet yang peneliti kaji sebagai acuan atau referensi.

Dalam penelitiannya, Iksan Santoso (2014) "Perancangan Instalasi Listrik pada Blok Pasar Modern dan Apartemen Di Gedung Kawasan Pasar Terpadu Blimbing Malang" dalam instalasi penerangan buatan ditentukan intensitas penerangan (lux) dan kapasitas AC pada instalasi daya listrik yang sesuai dengan fungsi ruang. [5] Untuk penentuan kabel sebesar 1,25 kali besar arus nominal sebagai arus nominal sebagai factor keamanan. Gedung ini membutuhkan daya sebesar 669.490 VA yang dibagi menjadi 5 MEE. MEE condotel sebesar 224580 VA, MEE Apartemen 156117 VA, MEE 1 sebesar 126000 VA, MEE 2 sebesar 124560 VA dan untuk motor sebesar 37333 VA. Dengan drop tegangan dibeban dari MDP yaitu sebesar 7,41 volt atau sebesar 3,37\%.

Dalam penelitiannya, M. Hariansyah (2015) "Perancangan dan Pemasangan Instalasi Listrik Penerangan dan Tenaga di Gedung Workshop PT. Basuh Power Electric". Setelah menganalisa peneliti mendapatkan jumlah lampu yang dibutuhkan untuk penerangan pada gedung A sebanyak 21 unit, menghasilkan kuat penerangan cahaya 250 lux menggunakan lampu induksi BMX 120 watt, dan gedung B sebanyak 28 unit menghasilkan kuat penerangan cahaya 250 lux, menggunakan lampu jenis jenis induksi 342, 150 watt. Jumlah kabel yang dibutuhkan terdiri dari kabel penerangan jenis NYM $3 \times 2,5 \mathrm{~mm}^{2}$, sebanyak 50 roll dan kabel tenaga NYY $4 \times 6 \mathrm{~mm}^{2}$ sebanyak 2 roll. [3]
Dalam penelitiannya, Ronal Yulianto dan Ira Musfira (2017) “ Perancangan Instalasi Listrik Gedung Sekolah Dasar Islam (SDi) Khalifah Kelurahan Donggala Kodi Kecamatan Ulujadi Kota Palu". Peneliti mendapatkan daya total dari instalasi listrik gedung ini adalah 61420 Watt atau 76775 VA, dan untuk supplai listrik diambil dari PLN yaitu listrik 3-phase dengan kapasitas 85.000 VA. Penghantar yang digunakan pada instalasi ini menggunakan kabel dengan jenis NYA, NYM dan NYY. Pengaman yang digunakan pada instalasi ini terdiri dari 2 jenis, yaitu MCB \& NFB, selain itu sistem instalasi Gedung ini juga diberi kotak PHB untuk untuk memudahkan dalam maintenance dan perbaikan apabila terjadi kerusakan. Dengan memperhitungkan faktor ekonomis dan keamanan instalasi maka total Rancangan Anggaran Biaya (RAB) pada perancangan instalasi gedung SDi Khalifah adalah Rp. 236.333.000,-. [6]

Berdasarakan beberapa penelitian sebelumnya seperti yang tertulis diatas, penulis akan mencoba mengangkat penelitian mengenai Perancangan instalasi Listrik Gedung Markas Komando Direktorat Kepolisian Perairan dan Udara Kepolisian Daerah Sulawesi Tengah di Desa Wani.

\subsection{Landasan Teori}

\subsubsection{Pengertiaan Instalasi Listrik}

Instalasi listrik merupakan suatu perlengkapan yang digunakan untuk menyalurkan energi listrik dari sumber listrik ke titik - titik beban. Titik beban yang dimaksud diantaranya beban resistif yang bisa berupa setrika, solder, lampu pijar, dan sebagainya, beban induktif yang bisa berupa kipas angin, lampu TL, mesin bor dan sebagainya serta beban kapasitif yang contohnya kapasitor. Instalasi listrik sangat penting untuk dilakukan terutama untuk 
konstruksi bangunan yang sudah direncanakan sebelumnya. Agar bangunan dapat memenuhi keselamatan, kenyamanan, berfungsi dan dihuni dengan baik, tentunya dalam instalasi listrik diperlukan perencanaan lewat gambar instalasi listrik dengan mengacu pada aturan - aturan yang sudah ditetapkan dalam kelistrikan. [4]

\subsubsection{Ketentuan Umum Instalasi Listrik}

Rancangan suatu sistem instalasi listrik harus memenuhi ketentuan Persyaratan Umum Instalasi Listrik (PUIL 2011) dan peraturan lain seperti :

a. Undang-Undang Nomor 1 tahun 1970 tentang keselamatan kerja, beserta peraturan pelaksanaannya.

b. Undang-Undang Nomor 30 tahun 2009 tentang Ketenaga listrikan

c. Peraturan Pemerintah No 14 Tahun 2012 Tentang penyediaan dan pemanfaatan tenaga listrik.

d. Peraturan Pemerintah No 62 Tahun 2012 tentang Usaha Penunjang Tenaga Listrik.

e. Peraturan Menteri Pertambangan dan Energi No 01.P/40/M.PE/1990 tentang instalasi ketenaga listrikan.

f. Peraturan lain mengenai kelistrikan yang berlaku dan tidak bertentangan dengan PUIL 2011 (misalnya standar-standar PLN).

Dalam perancangan sistem instalasi listrik harus diperhatikan tentang keselamatan manusia, makhluk hidup lain dan keamanan harta benda dari bahaya dan kerusakan yang bisa ditimbulkan oleh penggunaan instalasi listrik. Selain itu, berfungsinya instalasi listrik harus dalam keadaan baik dan sesuai dengan maksud penggunaannya.

\subsubsection{Prinsip Dasar Instalasi Bangunan}

Agar instalasi listrik yang dipasang dapat digunakan secara optimum, maka ada beberapa prinsip dasar yang perlu sebagai bahan pertimbangan yaitu paling tidak memenuhi $5 \mathrm{~K}+\mathrm{E}$ (Keamanan, Keandalan, Ketersediaan, Ketercapaian, Keindahan dan Ekonomis).

\subsubsection{Langkah - Langkah Perancangan Umum}

Langkah - langkah perancangan umum diantaranya :

a. Menentukan denah bangunan, letak beban listrik dan besarnya beban.

b. Menetapkan penyuplaian tenaga listrik, apakah tenaga listrik disuplai oleh PLN atau dibangkitkan sendiri, apakah pembangkit sendiri sebagai cadangan dan apakah untuk menyuplai seluruh beban atau hanya sebagian. Bila pembangkit sendiri perlu ditentukan pola pengoperasiannya.

c. Menentukan daya, jumlah dan tempat panel pembagi. Panel pembagi sebaiknya ditempatan di titik pusat beban yang tersambung.

d. Menentukan sistem pengamanan terhadap tegangan sentuh, terhadap arus lebih, arus hubung pendek dan terhadap beban lebih seerta sistem pembumian (arde / grounding).

e. Membuat daftar perlengkapan yang diperlukan bagi instalasi listrik. Dalam hal ini faktor keamanan pengoperasian dan penyesuaian terhadap standar telah terpenuhi, termasuk faktor ekonomi. Pastikan bahwa daya dari beban dan perlengkapan instalasi telah memenuhi kebutuhan.

\subsubsection{Berkas Perancangan Instalasi Listrik}


Dalam perencanaan instalasi listrik pada suatu gedung atau bangunan, berkas rancangan instalasi listrik terdiri dari :

\section{a. Denah Lokasi}

Yang menunjukan gambar posisi gedung yang akan dipasang instalasi listriknya. Data yang perlu ditulis pada gambar situasi ini adalah alamat lengkap, jarak terhadap sumber listrik terdekat (tiang listrik atau bangunan yang sudah berlistrik) untuk daerah yang sudah ada jaringan listriknya. Bila belum ada jaringan listriknya, perlu digambarkan rencana pemasangan tiang-tiang listrik.

\section{b. Gambar Instalasi}

Yang menunjukan gambar denah gedung (pandangan atas) dengan rencana tata letak instalasi penerangan dan rencana hubungan pada saklar.

\section{c. Diagram Garis Tunggal}

Yang menunjukan gambar satu garis dari APP (Alat Pembatas dan Pengukur) ke PHB (Panel Hubung Bagi) utama yang di distribusikan ke beberapa group langsung ke beban (untuk bangunan berkapasitas kecil) dan melalui panel cabang (SDP) maupun sub panel cabang (SSDP) baru ke beban. Pada diagram garis tunggal ini selain pembagian group pada PHB utama / cabang / sub cabang juga menginformasikan jenis beban, ukuran dan jenis penghantar, ukuran dan jenis pengaman arusnya, dan sistem pembumian / pentanahannya.

\subsubsection{Pencahayaan}

a. Pemilihan Lampu

Dalam perancangan instalasi listrik ini, perancang memilih menggunakan jenis lampu yang hemat energi, yaitu jenis SL (Spot Light) dan lampu TL (Tubular Lamp) dikarenakan penggunaan daya listrik lebih efisien dan cocok sebagai penerangan di gedung kantor kepolisian.

b. Pemilihan Armatur dan Jumlah Titik Cahaya

Penyebaran dari suatu cahaya bergantung pada konstruksi sumber cahaya itu sendiri dan armatur yang digunakan. Sebagian besar cahaya yang direspon mata tidak langsung di sumber cahaya, tetapi setelah dipantulkan atau melalui benda yang tembus cahaya.

Perancangan penerangan buatan dapat dilakukan perhitungan dengan metode Lumen.

Metode lumen adalah menghitung intensitas penerangan rata-rata pada bidang kerja. Fluks cahaya diukur pada bidang kerja, yang secara umum mempunyai tinggi antara $75-90 \mathrm{~cm}$ diatas lantai. Besarnya intensitas penerangan bergantung dari jumlah fluks cahaya dari luas bidang kerja yang dinyatakan dalam lux.

Tidak semua cahaya dari lampu mencapai bidang kerja, karena ada yang dipantulkan dan diserap oleh dinding, plafon dan lantai. Faktor refleksi dinding dan faktor refleksi plafon merupakan bagian cahaya yang dipantulkan oleh dinding dan langit-langit atau plafon yang kemudian mencapai bidang kerja.

Indeks ruang $(\mathrm{K})$

$\mathrm{K}=\frac{p \cdot l}{h(p+l)}$ (Rumus 2.1)

Keterangan :

$\mathrm{P}=$ Panjang ruangan $(\mathrm{m})$

$\mathrm{L}=$ Lebar ruangan $(\mathrm{m})$

$\mathrm{h}=$ Tinggi sumber cahaya dari bidang kerja (m) 
Indeks ruang dihitung berdasarkan dimensi ruangan yang akan diberi penerangan cahaya lampu. Nilai $\mathrm{K}$ hasil perhitungan digunakan untuk menentukan nilai efisiensi penerangan lampu.

$\eta=\eta 1+\frac{K-K 1}{K 2-K 1}(\eta 2-\eta 1) \ldots($ Rumus 2.2$)$

Keterangan :

$\mathrm{K}=$ Indeks Ruangan

K1 = Nilai terkecil yang mendekati dari nilai indeks ruangan

K2 = Nilai terbesar yang mendekati dari nilai indeks ruangan

$\eta \quad=$ Efisiensi penerangan

$\eta 1=$ Nilai refleksi langit - langit dari K1

$\eta 2=$ Nilai refleksi langit - langit dari K2

Rumus tersebut digunakan untuk mencari efisiensi penerangan lampu (armature) dengan menggunakan acuan pada tabel efisiensi $(\eta)$.

Untuk menentukan jumlah armatur atau jumlah lampu dari suatu ruangan yang akan diberi penerangan buatan dapat dihitung dengan rumus :

$\mathrm{n}=\frac{E \times A}{\phi_{\text {lampu }} \times \eta}$

Keterangan :

$\mathrm{n} \quad=$ Jumlah Armatur

$\mathrm{E}=$ Intensitas penerangan pada bidang kerja (lux)

A $\quad=$ Luas bidang kerja $\left(\mathrm{m}^{2}\right)$

$\phi_{\text {lampu }}=$ Flux lampu (lumen)

$\eta \quad=$ Efisiensi Armatur

\subsubsection{KKB dan KKK}

Dalam PUIL 2011, dinamakan KKB (Kotak Kontak Biasa) dan KKK (Kotak Kontak Khusus). KKB adalah kotak kontak biasa yang dipasang untuk digunakan sewaktu-waktu (tidak secara tetap) bagi piranti listrik jenis apapun yang memerlukannya, asalkan penggunaannya tidak melebihi batas kemampuannya. KKB tersebar diseluruh bangunan dengan beban tidak tetap dan biasanya jadi satu dengan group untuk penerangan.

\subsubsection{Saklar}

Saklar adalah suatu komponen atau perangkat yang digunakan untuk memutuskan atau menghubungkan aliran listrik. Saklar dinding biasanya ditempatkan kurang lebih $120 \mathrm{~cm}$ di atas lantai pada jalan yang biasa dilalui. Jika harus digunakan dengan membuka pintu terlebih dahulu, maka sakelar ditempatkan didekat dan disisi daun pintu yang membuka.

Saklar yang digunakan ialah saklar seri dan saklar tunggal.

\subsubsection{Penghantar}

Untuk instalasi listrik, penyaluran arus listrik dari panel ke beban maupun sebagai pengaman (grounding) digunakan penghantar listrik yang sesuai dengan penggunannya. Kabel instalasi yang biasa digunakan pada instalasi penerangan, jenis kabel yang banyak digunakan dalam instalasi rumah tinggal untuk pemasangan tetap ialah NYA dan NYM. Pada penggunannya kabel NYA menggunakan pipa untuk melindungi secara mekanis ataupun melindungi dari air dan kelembaban yang dapat merusak kabel tersebut.

Adapun jenis kabel yang digunakan adalah Kabel NYM dan Kabel NYY.

Perhitungan arus nominal (I) untuk 3 fasa dapat dirumuskan sebagai berikut : 
$\mathrm{I}=\frac{P}{\sqrt{3} \times v \times \cos \varphi}$

(Rumus 2.4)

Dimana :

$$
\begin{array}{ll}
\mathrm{I} & =\text { Arus Nominal } \\
\mathrm{P} & =\text { Daya Aktif } \\
\mathrm{V} & =\text { Tegangan Line } 380 \text { Volt }
\end{array}
$$

$\operatorname{Cos} \varphi=0,8$

\subsubsection{Panel Hubung Bagi (PHB)}

PHB adalah panel hubung bagi atau papan hubung bagi atau panel berbentuk lemari (cubicle), yang dapat dibedakan sebagai :

\section{a. Panel Utama / MDP : Main Distribution Panel}

b. Panel Cabang / SDP : Sub Distribution Panel

c. Panel Beban / SSDP : Sub-sub Distribution Panel

Di dalam panel biasanya busbar atau rel dibagi menjadi dua bagian yang saling berhubungan dengan saklar pemisah, yang satu mendapat saluran masuk dari pengusaha ketenaga listrikan (PLN) dan satunya lagi dari sumber listrik sendiri (genset). Dari kedua busbar didistribusikan ke beban secara langsung atau melalui SDP dan atau SSDP. Tujuan busbar dibagi menjadi dua segmen ini adalah jika sumber listrik dari PLN mati akibat gangguan ataupun karena pemeliharaan, maka suplai ke beban tidak akan terganggu dengan adanya sumber listrik sendiri (genset) sebagai cadangan.

\subsubsection{Sistem Pentanahan}

Sistem pentanahan adalah sistem hubungan penghantar yang menghubungkan sistem, badan peralatan dan instalasi dengan bumi / tanah sehingga dapat mengamankan manusia dari sengatan listrik, karena dengan adanya sistem pentanahan beda tegangan yang di hasilkan akan $\leq 50 \mathrm{~V}$ yang merupakan tegangan sentuh yang aman bagi manusia, dan mengamankan komponenkomponen instalasi dari bahaya tegangan / arus tidak normal. Oleh karena itu, sistem pentanahan menjadi bagian esensial dari sistem tenaga listrik.

\section{HASIL DAN PEMBAHASAN}

\subsection{Lokasi dan Waktu Penelitian}

Pelaksanaan penelitian dilakukan pada Gedung Markas Komando Direktorat Kepolisian Perairan dan Udara Kepolisian Daerah Sulawesi Tengah berlokasi di Desa Wani Kecamatan Tawaeli Kabupaten Donggala dan pada tanggal 18 Agustus hingga selesai.

\subsection{Bahan dan Alat Penelitian}

Adapun alat bahan yang digunakan dalam penelitian "Perancangan Instalasi Listrik Gedung Markas Komando Direktorat Kepolisian Perairan dan Udara Kepolisian Daerah Sulawesi Tengah di Desa Wani" adalah sebagai berikut :

Adapun diagram alir (Flowchart) rencana penelitian yang akan dilakukan adalah : 


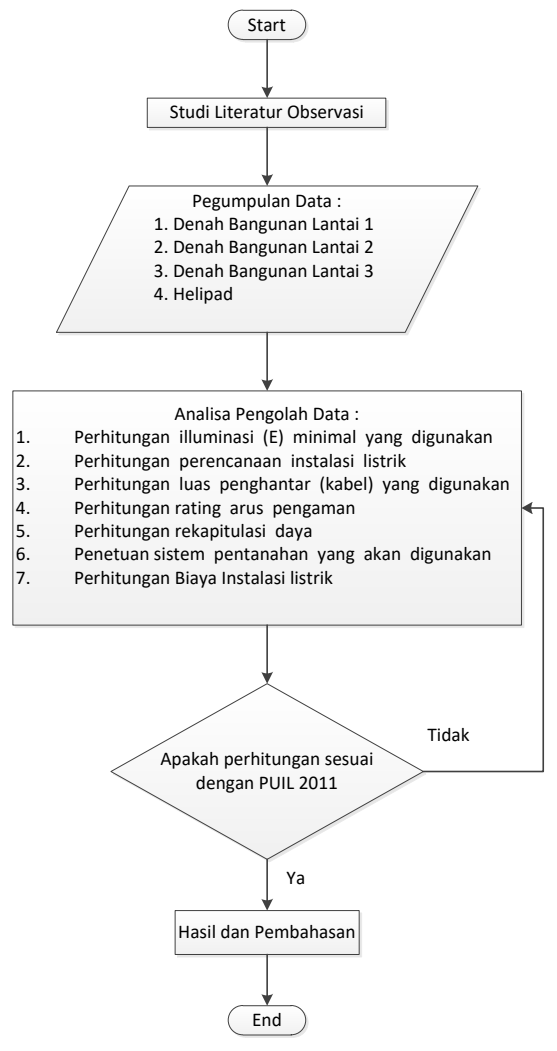

Gambar 3.1 Diagram Alir (Flowchart)

\subsubsection{Penentuan Gambar Denah Bangunan}

Bangunan ini di bangun diatas tanah seluas $\pm 2100 \mathrm{~m}^{2}$ dengan tinggi bangunan \pm $12 \mathrm{~m}$, yang terdiri dari 3 lantai dan Helipad, yangmana di lantai 1 terdapat 45 ruangan diantaranya ruang kerja, gudang toilet, ruang sholat, penjara, koridor dan ruangan lainnya. Di lantai 2 terdapat 25 ruangan diantaranya ruangan kerja direktur dan wakil direktur, koridor, toilet, ruang rapat, ruang kerja dan ruangan lainnya. Kemudian di lantai 3 terdapat ruangan serbaguna, dak Beton disisi timur dan sisi barat. Serta diatas lantai 3 terdapat Helipad. Dengan total 72 ruangan ditambah beberapa tempat yang terdapat titik instalasi penerangan.
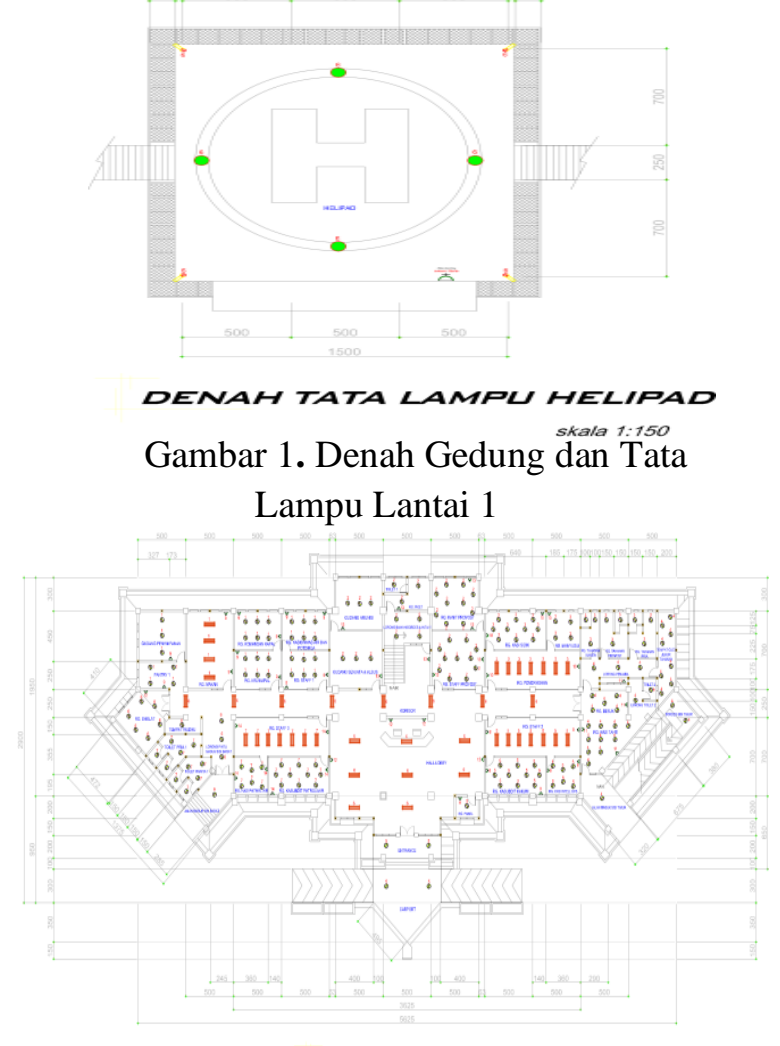

Denah tata Lampl Lt.
Gambar 2. Denah Gedung dan Tata Lampu

Lantai 2

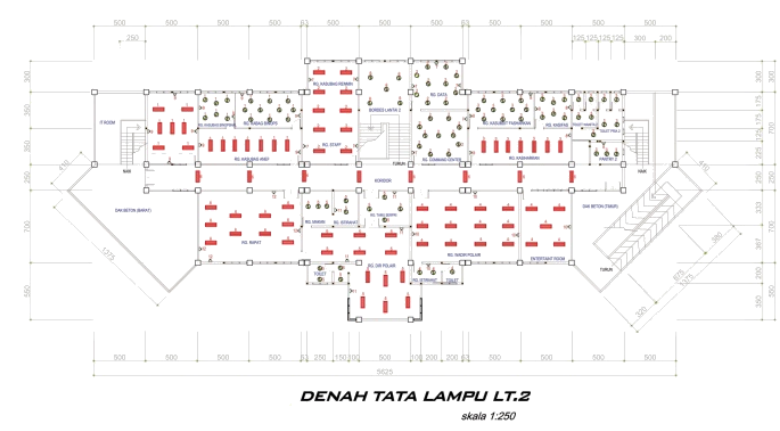

Gambar 3. Denah Gedung dan Tata Lampu Lantai 3

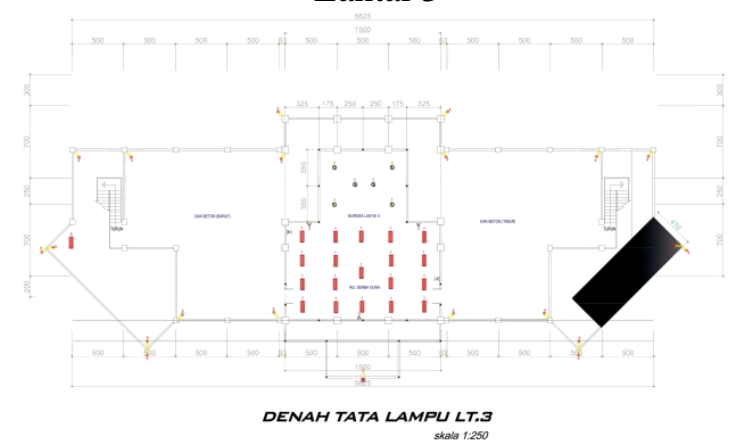

Gambar 4. Denah Gedung dan Tata Lampu Helipad 


\subsubsection{Menentukan Jumlah Armatur dan Lampu yang Digunakan Pada Ruangan}

Adapun perhitungan yang penulis lakukan dalam perancangan dapat dilihat pada tabel :

Tabel 1 Hasil Perhitungan flux lampu dan daya

\begin{tabular}{|c|c|c|c|c|c|}
\hline \multirow{3}{*}{ No. } & \multirow{3}{*}{$\begin{array}{c}\text { Nama } \\
\text { Ruangan }\end{array}$} & \multirow{3}{*}{$\begin{array}{c}\text { Luas } \\
\text { Ruangan } \\
\left(\mathbf{m}^{2}\right)\end{array}$} & \multicolumn{2}{|c|}{$\begin{array}{c}\text { Jenis } \\
\text { Lampu }\end{array}$} & \multirow{2}{*}{ Daya } \\
\hline & & & SL & TL & \\
\hline & & & $\begin{array}{l}20 \\
w\end{array}$ & $\begin{array}{c}2 x \\
36 \\
w\end{array}$ & (watt) \\
\hline 1 & $\begin{array}{l}\text { Gudang } \\
\text { Penyimpanan }\end{array}$ & 22.5 & 3 & & 60 \\
\hline 2 & Pantry 1 & 12.5 & 4 & & 80 \\
\hline 3 & Rg. Makan & 35 & & 4 & 288 \\
\hline 4 & $\begin{array}{l}\text { Rg. Komandan } \\
\text { Kapal }\end{array}$ & 17.5 & 6 & & 120 \\
\hline 5 & Rg. Kru Kapal & 17.5 & 6 & & 120 \\
\hline 6 & $\begin{array}{l}\text { Rg. } \\
\text { Kasibinmas } \\
\text { Air dan } \\
\text { Potdirga }\end{array}$ & 17.5 & 6 & & 120 \\
\hline 7 & Rg. Staff 1 & 17.5 & 6 & & 120 \\
\hline 8 & $\begin{array}{l}\text { Gudang } \\
\text { Amunisi }\end{array}$ & 25 & 3 & & 60 \\
\hline 9 & $\begin{array}{l}\text { Gudang } \\
\text { Senjata \& } \\
\text { Alsus }\end{array}$ & 28 & 3 & & 60 \\
\hline 10 & Toilet 1 & 3.75 & 1 & & 20 \\
\hline 11 & Rg. Piket & 11.25 & 2 & & 40 \\
\hline 12 & $\begin{array}{l}\text { Lorong Bordes } \\
\text { Lantai } 1\end{array}$ & 35 & 4 & & 80 \\
\hline 13 & $\begin{array}{l}\text { Rg. Kanit } \\
\text { Provost }\end{array}$ & 25 & 10 & & 200 \\
\hline 14 & Rg. Staff & 28 & 11 & & 220 \\
\hline
\end{tabular}

\begin{tabular}{|c|c|c|c|c|c|}
\hline & Provost & & & & \\
\hline 15 & Rg. Kasi Sidik & 22.75 & 10 & & 200 \\
\hline 16 & Rg. Menyusui & 12.25 & 4 & & 80 \\
\hline 17 & $\begin{array}{l}\text { Rg. } \\
\text { Pemeriksaan }\end{array}$ & 35 & & 7 & 504 \\
\hline 18 & $\begin{array}{l}\text { Rg. Tahanan } \\
\text { Wanita }\end{array}$ & 8.5 & 3 & & 60 \\
\hline 19 & $\begin{array}{l}\text { Rg. Tahanan } \\
\text { Provost }\end{array}$ & 12.75 & 3 & & 60 \\
\hline 20 & $\begin{array}{l}\text { Rg. Tahanan } \\
\text { Pria }\end{array}$ & 12.75 & 3 & & 60 \\
\hline 21 & Lorong Penjara & 14 & 3 & & 60 \\
\hline 22 & $\begin{array}{l}\text { T. Cuci \& } \\
\text { Jemur Tahanan }\end{array}$ & 14 & 8 & & 160 \\
\hline 23 & Toilet 2 & 4 & 1 & & 20 \\
\hline 24 & $\begin{array}{l}\text { Lorong Toilet } \\
2\end{array}$ & 7.5 & 1 & & 20 \\
\hline 25 & $\begin{array}{l}\text { Bordes Sisi } \\
\text { Timur }\end{array}$ & 15 & 2 & & 40 \\
\hline 26 & $\begin{array}{l}\text { Jalan Masuk } \\
\text { Sisi Timur }\end{array}$ & 11.685 & 1 & & 20 \\
\hline 27 & Rg. Kasi Tahti & 25 & 10 & & 200 \\
\hline
\end{tabular}

4.1.3 Penentuan Panel dan Pembagian Grup Beban

Pada panel utama terdiri dari NFB utama, MCB 3 Fasa Pompa Air dan NFB Kotak Kontak 32 A, NFB penerangan lantai 1, NFB AC Lantai 1, NFB penerangan lantai 2, NFB AC Lantai 2 dan Lantai 3, MCB 3 Fasa penerangan lantai 3 yang kemudian di bagi ke NFB setiap panel penerangan dan panel AC. Dari NFB pembagi kemudian masuk ke MCB tiap grup.

Panel penerangan lantai 1 terdiri dari 14 grup dan panel AC lantai 1 terdiri dari 21 grup. Panel penerangan lantai 2 terdiri dari 12 grup dan panel AC lantai $2 \& 3$ terdiri dari 20 grup. Panel penerangan lantai 3 


\section{Jurnal Ilmiah Foristek

terdiri dari 6 grup. Pembagian grup berdasarkan penerangan dalam ruangan maupun diluar ruangan.

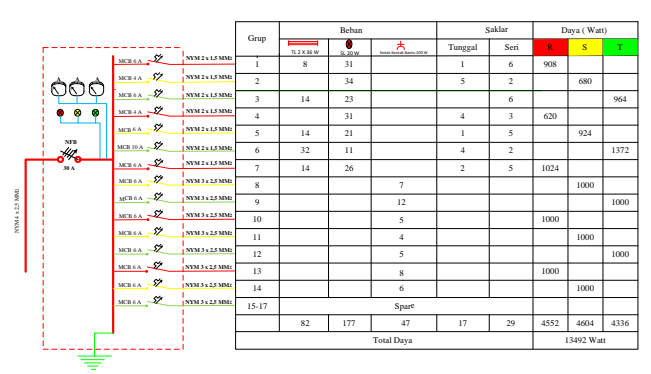

Gambar 5. Tabel Diameter Kabel dan Pengaman Panel Penerangan Lantai 1

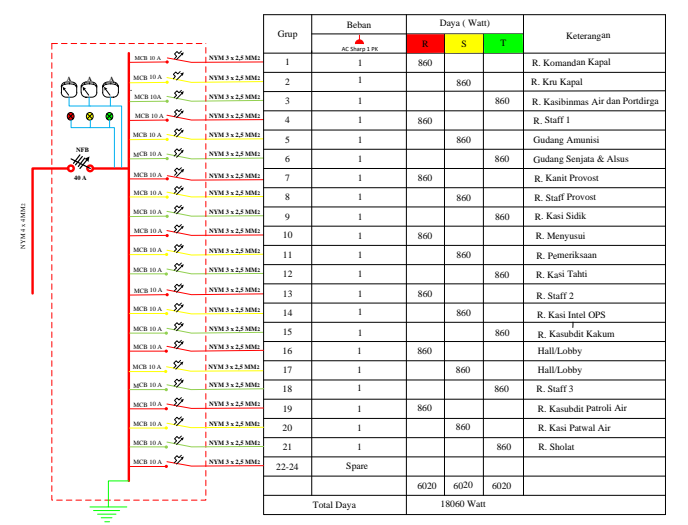

Gambar 6. Tabel Diameter Kabel dan Pengaman Panel AC Lantai 1

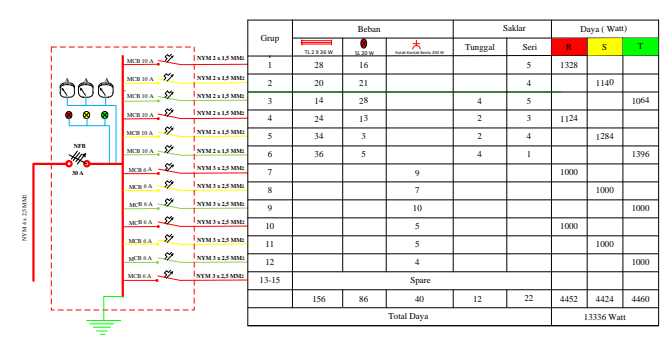

Gambar 7. Tabel Diameter Kabel dan Pengaman Panel Penerangan Lantai 2

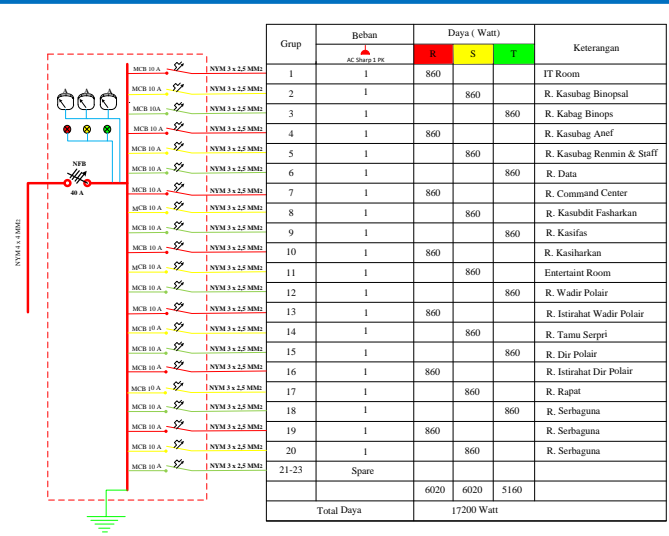

Gambar 8. Tabel Diameter Kabel dan Pengaman Panel AC Lantai $2 \& 3$

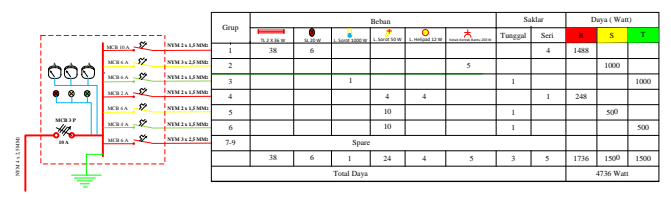

Gambar 9. Tabel Diameter Kabel dan Pengaman Panel Penerangan Lantai 3

\subsubsection{Perhitungan Diameter Penghantar, Rating Pengaman yang Digunakan serta Rekapitulasi Daya Penerangan maupun Tenaga}

Untuk menghindari terjadinya kerusakan pada sebuah penghantar, maka luas penampang penghantar harus diperhitungkan dengan teliti. Kerusakan pada sebuah penghantar dapat diakibatkan oleh arus yang melalui penghantar tersebut melebihi kapasitas Kapasitas Hantar Arus atau KHAnya.

Untuk nilai diameter kabel, referensi yang penulis gunakan adalah PUIL 2011 pada tabel 7.3-4 dan 7.3-5a tentang nilai diameter kabel sesuai dengan perhitungan KHA yang didapatkan dan juga pada Penjelasan PUIL 2011 Edisi 2014.

Jadi, total daya panel penerangan lantai 1 adalah 13.492 watt, total daya panel penerangan lantai 2 adalah 13.336 watt, total daya panel penerangan lantai 3 adalah 4.736 watt, total daya panel AC lantai 1 adalah 
18.060 watt, total daya panel AC lantai 2 dan 3 adalah 17.200 watt, total daya pada pompa air sebesar 4.416 watt dan daya beban maximum untuk kotak kontak industri sebesar 16.849,39 watt. Maka total daya keseluruhan adalah 88.089,39 watt.

Maka,

$\mathrm{I}=\frac{P}{\sqrt{3} \times V \times \cos \varphi}$

$\mathrm{I}=\frac{88089,39}{\sqrt{3} \times 380 \times 0,8}=\frac{88089,39}{526,5}=167,3 \mathrm{~A} \approx \mathrm{NFB}$ 175 Ampere

Dari perhitungan arus nominal pada PHB Utama diatas didapatkan hasil 167,3 Ampere, maka diperoleh ukuran KHA ialah 185. Sedangkan ukuran penghantar yang cocok ialah NYM 4 x $50 \mathrm{~mm}^{2}$. Dan jenis pengaman yang digunakan ialah NFB dengan rating pengaman sebesar 175 Ampere

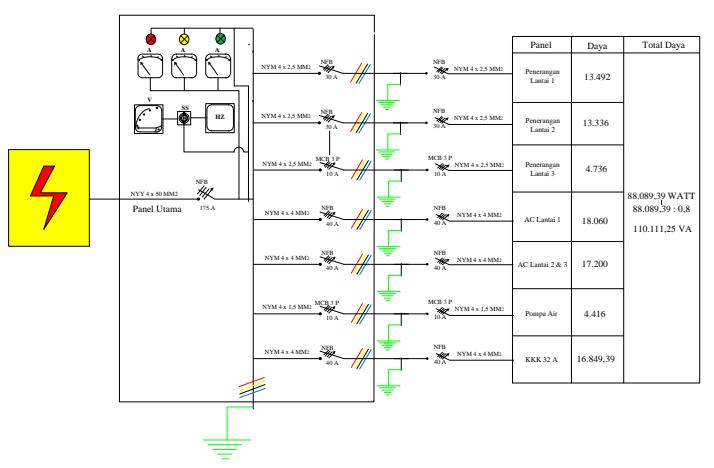

Gambar 10. Tabel Diameter Kabel dan Pengaman Panel Utama

\section{KESIMPULAN}

\subsection{Kesimpulan}

Dari hasil penelitian perencanaan Instalasi Gedung Markas Komando Direktorat Kepolisian Perairan dan Udara Kepolisian Daerah Sulawesi Tengah di Desa
Wani, maka dapat diperoleh kesimpulan sebagai berikut :

a. Seluruh sistem instalasi listrik ini mendapatkan supplai listrik 3 fasa dari PLN.

b. Total daya aktif pada gedung ini adalah 88.089,39 Watt, dengan menghasilkan arus sebesar 167,3 ampere. Jika daya aktif yang dikonsumsi keseluruhan dibagi dengan nilai $\operatorname{Cos} \varphi(0,8)$ menghasilkan 110.111,25 VA, maka daya yang dibutuhkan dari PLN untuk penyambungan sebesar $131.000 \mathrm{VA}$.

c. RAB total yang penulis dapatkan pada gedung ini adalah Rp. 522.717.250,-

d. Penghantar yang digunakan pada instalasi ini seluruhnya menggunakan kabel dengan jenis NYY dan NYM, dengan ukuran yang bervariasi sesuai dengan perhitungan KHA penghantar yang telah dilakukan.

e. Pengaman yang digunakan pada instalasi ini terdiri dari 2 jenis, yaitu MCB dan NFB yang ratingnya bervariasi sesuai dengan perhitungan yang telah dilakukan.

f. Nilai perhitungan tahanan pentanahan pada gedung untuk satu buah batang elektroda yang ditanam tegak lurus kedalam tanah adalah 13,215 Ohm. Agar memenuhi persyaratan yeng berlaku yaitu $\leq 2 \Omega$, maka dipelukan pemasangan 7 batang elektroda sepanjang 3 meter yang dipasang secara paralel.

\section{DAFTAR PUSTAKA}

[1] Abdila S, V., 2012, 'Perancangan Instalasi Listrik Gedung Clubhouse Di Dago Bandung', Dago, Bandung.

[2] Anggara, B., 2015, 'Perencanaan Instalasi Listrik Di Ruang Laboratorium Instalasi Listrik 
Politeknik Gajah Tunggal', Tangerang, Politeknik Gajah Tunggal.

[3] Hariansyah M. (2015) 'Perancangan dan Pemasangan Instalasi Listrik Penerangan dan Tenaga di Gedung Workshop PT. Basuh Power Electric', Bogor Universitas Ibn Khaldun Bogor.

[4] Panitia PUIL, SNI 04-0225-2011., 'Persyaratan Umum Instalasi Listrik 2011', Jakarta : Direktorat Penyelidikan Masalah Bangunan.

[5] Santoso, I., 2014, 'Perancangan Instalasi Listrik Pada Blok Pasar Modern Dan Apartemen Di Gedung Kawasan Pasar Terpadu Blimbing Malang ',Malang: Jurusan Teknik Elektro, Universitas Brawijaya.

[6] Yuianto, R \& Musfira, I, 2017, 'Perancangan Instalasi Listrik Gedung Sekolah Dasar Islam (Sdi) Khalifa Kelurahan Donggala Kodi Kecamatan Ulu Jadi Kota Palu', Palu :Jurusan Teknik Elektro, Universitas Tadulako. 